\title{
Knockout of ABC Transporter ABCG4 Gene Confers Resistance to Cry1 Proteins in Ostrinia furnacalis
}

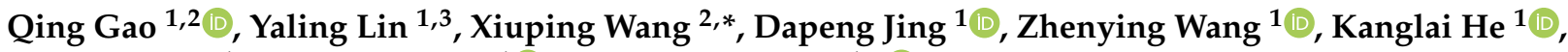 \\ Shuxiong Bai ${ }^{1}$, Yongjun Zhang ${ }^{1} \mathbb{D}$ and Tiantao Zhang ${ }^{1, *(1)}$
}

1 State Key Laboratory for the Biology of the Plant Diseases and Insect Pests, Institute of Plant Protection, Chinese Academy of Agricultural Sciences, Beijing 100193, China; gaoqing3399@163.com (Q.G.); linyaling95@163.com (Y.L.); jingfly6@163.com (D.J.); zywang@ippcaas.cn (Z.W.); klhe@ippcaas.cn (K.H.); sxbai@ippcaas.cn (S.B.); yjzhang@ippcaas.cn (Y.Z.)

2 College of Agronomy and Biotechnology, Hebei Normal University of Science and Technology, Qinhuangdao 066000, China

3 College of Plant Protection, Gansu Agriculture University, Lanzhou 730070, China

* Correspondence: wang3481@hevttc.edu.cn (X.W.); zhangtiantao@caas.cn (T.Z.)

check for updates

Citation: Gao, Q.; Lin, Y.; Wang, X.; Jing, D.; Wang, Z.; He, K.; Bai, S.; Zhang, Y.; Zhang, T. Knockout of ABC Transporter ABCG4 Gene Confers Resistance to Cry1 Proteins in Ostrinia furnacalis. Toxins 2022, 14, 52. https://doi.org/10.3390/ toxins 14010052

Received: 9 December 2021

Accepted: 8 January 2022

Published: 12 January 2022

Publisher's Note: MDPI stays neutral with regard to jurisdictional claims in published maps and institutional affiliations.

Copyright: (C) 2022 by the authors. Licensee MDPI, Basel, Switzerland. This article is an open access article distributed under the terms and conditions of the Creative Commons Attribution (CC BY) license (https:// creativecommons.org/licenses/by/ $4.0 /)$.

\begin{abstract}
Ostrinia furnacalis is an important borer on maize. Long-term and large-scale planting of transgenic corn has led O. furnacalis evolving resistance and reducing the control effect. Recently, high levels of resistance to Bt Cry1 toxins have been reported to be genetically linked to the mutation or down-regulation of $\mathrm{ABC}$ transporter subfamily $\mathrm{G}$ gene $A B C G 4$ in O. furnacalis. In order to further determine the relationship between $A B C G 4$ gene and the resistance to Cry1 toxins in O. furnacalis, the novel CRISPR/Cas9 genome engineering system was utilized to successfully construct ABCG4-KO knockout homozygous strain. Bioassay results indicated that an ABCG4-KO strain had a higher resistance to Cry1 proteins compared with a susceptible strain (ACB-BtS). The result indicates that the $A B C G 4$ gene may act as a receptor of the Bt Cry1 toxin in O. furnacalis. Furthermore, the development time was significantly changed in the early stage ABCG4-KO larvae, and the population parameters were also significantly changed. In summary, our CRISPR/Cas9-mediated genome editing study presents evidence that $A B C G 4$ gene is a functional receptor for Bt Cry1 toxins, laying the foundation for further clarification of the Bt resistance mechanism.
\end{abstract}

Keywords: CRISPR; ABCG4; Ostrinia furnacalis; resistant; Cry1 proteins

Key Contribution: $A B C G 4$ gene is proved as a receptor of Cry1 toxins. Knocking out of $A B C G 4$ gene can directly increase the resistant of ACB to Cry1 toxins, and the development time and other life parameters are significantly increased.

\section{Introduction}

The Asian corn borer (ACB), Ostrinia furnacalis (Lepidoptera: Crambidae), is a worldwide agricultural pest that causes damage from East and Southeast Asia to the Western Pacific islands [1]. Larvae are the main pest on maize and seriously occurring in China [2]. Chemical insecticides are used to control O. furnacalis, which has led to several problems, including environmental pollution, the occurrence of resistance, and loss of biodiversity [3]. Bacillus thuringiensis (Bt) is a ubiquitous gram-positive bacterium, which can specifically kill target pests and is harmless to non-target insects [4]. Bt crops can not only protect the ecological environment but also increase the economic benefits [5]. Therefore, $\mathrm{Bt}$ bio-insecticides are a substitute for chemical insecticides for pest control. Bt produces insecticidal crystalline proteins during sporulation. The crystalline proteins are dissolved to a fragment after being ingested by an insect. The active fragments are processed by a proteolytic enzyme, binding to specific receptors on the brush boundary membrane of the midgut epithelium. The osmotic balance is destroyed, the epithelial cells are dissolved, and 
they damage the midgut, eventually causing larval death [6,7]. Bt toxin receptors play an important role in toxin specificity and toxicity, and mutations in these genes lead to high levels of resistance in many insect species. Bt resistance has been reported in lepidoptera and many other insects. Plutella xylostella was the first documented pest that developed Bt resistance in the field, repeated application of Bt protein insecticide produced significant resistance in P. xylostella [8-12].

Insects can quickly evolve resistance to Bt crops, and the efficacy of an extraordinarily specific and environmentally safe microbial insecticide may be rapidly lost to pest resistance if $\mathrm{Bt}$ is not deployed wisely $[13,14]$. A recent study indicated that ABC transporters, the largest transport family in organisms, play a central role in the pest killing mechanism. Based on the sequence similarity of nucleotide binding domains (NBD) and transmembrane domains (TMDs), the ABC transporter family includes ABCA-ABCH subfamilies [15]. Some of these have been associated with resistance to xenobiotics. In Laodelphax striatellus, $\mathrm{ABCB} / \mathrm{C} / \mathrm{D} / \mathrm{G}$ genes were up-regulated in all three resistant strains, showing that $\mathrm{ABC}$ transporters might be involved in resistance to multiple insecticides [16]. In bed bugs, the $A B C$ transporters were significantly up-regulated in pyrethroid resistant larvae compared with the susceptible strain. Knocking down of two ABC transporters can significantly increase the susceptibility to pyrethroid [17]. Recently, after knocking out both $A B C C 2$ and $A B C C 3$ genes by CRISPR/Cas9, can cause high levels of resistance to Cry1 toxins in $P$. xylostella, which indicates that Bt resistance was genetically linked to the mutation or down-regulation of the two genes [18]. Jin et al. [19] indicated that resistance to Cry1 toxins was genetically linked to the mutation or down-regulation of $A B C C 2$ and $A B C C 3$ genes in Spodoptera frugiperda. Moreover, in Helicoverpa armigera, simultaneous knocking out of $A B C C 2$ and $A B C C 3$ genes produced high resistance to Bt toxin Cry1Ac. However, knocking out $A B C C 2$ genes on their own caused low resistance, whereas knocking out $A B C C 3$ genes alone caused no resistance [20]. There have been fewer reports about other ABC subfamily genes involved in Cry1 toxins resistance. ABC transporters have also been shown to affect insect growth and development. In Tribolium castaneum, ABCG and ABCH proteins have been shown to be involved in the transport of cuticle lipids, eye pigment precursors, and ecdysides [21]. After knocking down of TcABCG-4F gene, T. castaneum larvae died and growth period significantly increased during adult emergence [22]. Ewart et al. [23] indicated that an ABC transporter was found to be involved in Drosophila melanogaster eye pigment precursor transport. Tsuji et al. [24] successfully identified one gene that plays a major role in eye pigmentation white orthologs in Harmonia axyridis.

Many genes are down-regulated in resistant strains, resulting in reduced binding to Bt proteins and resistance increased. As in the previous report, the ABCG subfamily genes were shown to be significantly down-regulated in the Cry1Ac resistant strain and may be involved in Cry1 toxins resistance [25]. For further study on the function of the $A B C G$ subfamily genes in O. furnacalis, the CRISPR/Cas9 system was successfully used to knock out $A B C G 4$ gene to construct an ABCG4-KO strain. Cry1 toxins were used to test the effect of the ABCG4-KO strain compared with susceptible strains. The effects of knock out $A B C G 4$ gene in Asian corn borer on the growth and development were evaluated. Our result demonstrates a clear function of $A B C G 4$ gene in $O$. furnacalis.

\section{Results}

\subsection{Establishment of Homozygotes ABCG4-KO Knockout Strain}

After six generations (G5) of selection, a total of 120 males and females were detected by PCR and sequencing (Figure 1). In total, 80 individuals were successfully knocked out by the CRISPR/Cas9 system. The offspring of G5 were used to test the toxicity and development parameters. 
A

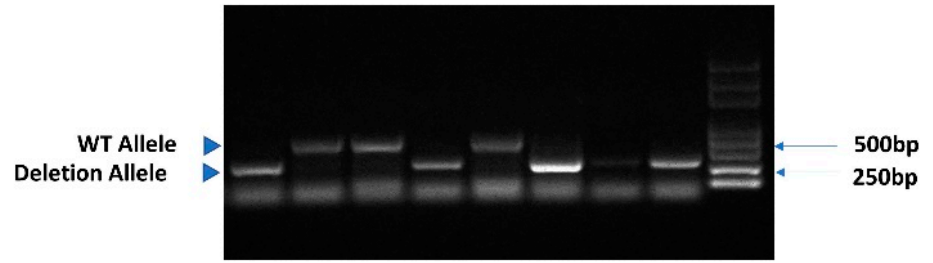

B
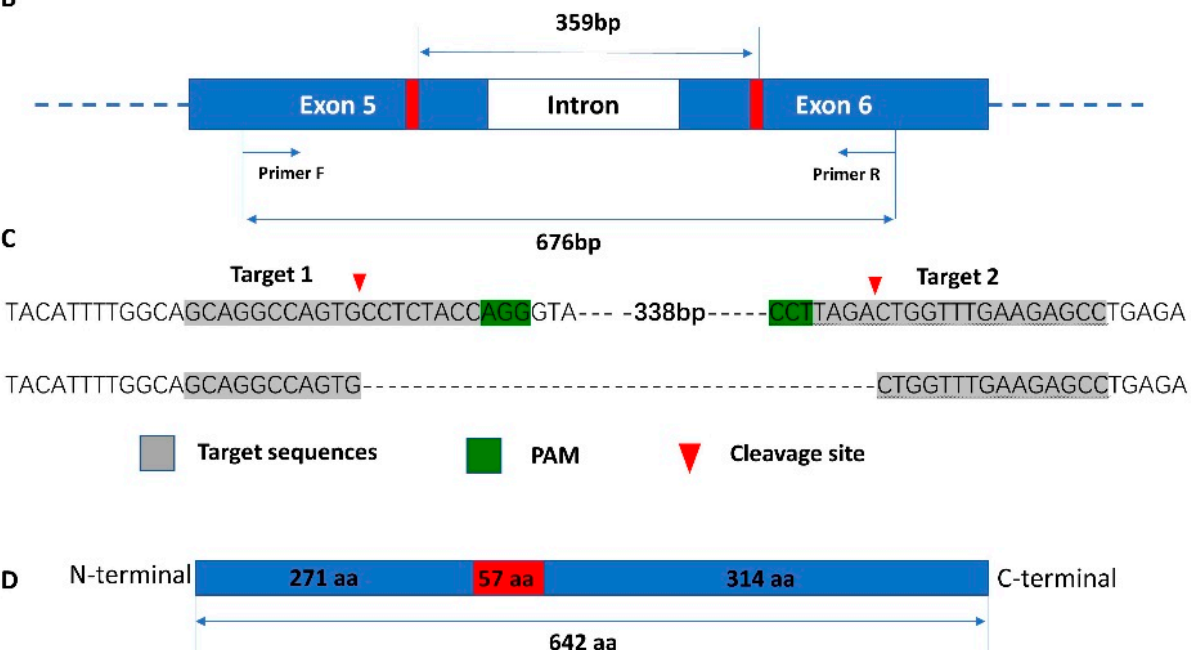

Figure 1. The gene knockout strategy for used CRISPR/Cas9 system in O. furnacalis. The gDNA (cleaved on Exon 5-6) fragments of ABCG4-KO (359 bp) were successfully detected using the gDNA extracted from leg and analyzed on $2 \%$ agarose gels (A). Schematic diagram exhibits the knockout fragment length by PCR amplification (B), sequencing detail of the cleavage site (C), and deletion fragment location on amino acid sequences (D). The deleted fragment is located on N-terminal.

\subsection{Resistance Level of ABCG4-KO Strain to Cry1 Proteins}

The resistance level of the ABCG4-KO strain to Cry1 proteins (Cry1Ab, Cry1Ac, Cry1Ah, Cry1Ie, and Cry1F) were tested by the bioassay method. The susceptible strain $\mathrm{ACB}-\mathrm{BtS}$ was used as control. Based on previous data from our lab, $\mathrm{LC}_{50}$ of Cry1Ab, Cry1Ac, Cry1Ah, Cry1F, and Cry1le virulence to ACB-BtS is $0.2 \mu \mathrm{g} / \mathrm{g}, 0.2 \mu \mathrm{g} / \mathrm{g}, 0.2 \mu \mathrm{g} / \mathrm{g}$, $0.5-0.7 \mu \mathrm{g} / \mathrm{g}$, and $3.0-5.0 \mu \mathrm{g} / \mathrm{g}$, respectively [26]. The biometric results showed the larval survival rates of the ABCG4-KO strain on the same $\mathrm{LC}_{50}$ concentration as the five Cry1 proteins were significantly higher than the ACB-BtS strain (Figure 2A-E). The larval survival rates of the ABCG4-KO and ACB-BtS strains on a normal artificial diet were both above $96 \%$ and there was no significant difference (Figure $2 \mathrm{~F}$ ).

\subsection{Larva and Pupal Development Duration and Adult Lifespan of ABCG4-KO and ACB-BtS Strain}

For each of the strains, ACB-BtS and ABCG4-KO, 144 newly hatched larvae reared on artificial diet were selected. In total, 121 and 134 individuals of each strain were survived to the fifth instar, respectively (Table 1). The development time of ABCG4-KO and ACB-BtS showed significant differences in the younger (1st and 2 nd) instar larvae. But there were no significant differences in other stages.

\subsection{Pupation Rate, Emergency Rate and Oviposition Numbers per Female of ABCG4-KO and $A C B-B t S$ Strains}

The susceptible strain ACB-BtS and knockout strain ABCG4-KO successfully emergence 111 and 102 individuals, respectively. ACB-BtS and ABCG4-KO had significant differences in the pupation rate. Moreover, emergency rate and oviposition numbers per female showed no significant difference between the two strains (Table 2). 
A

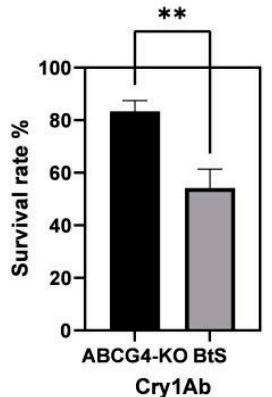

D

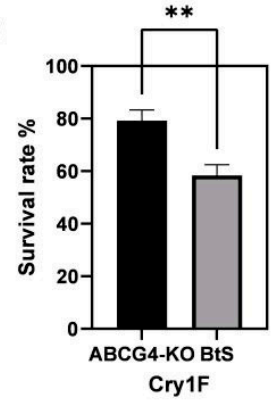

B

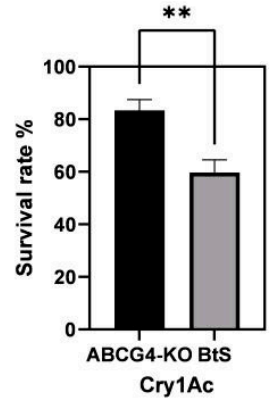

$E$

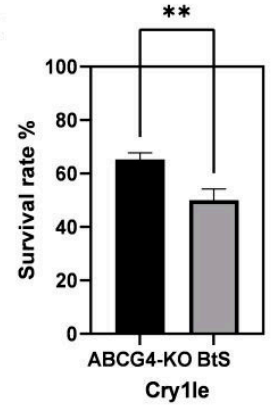

C

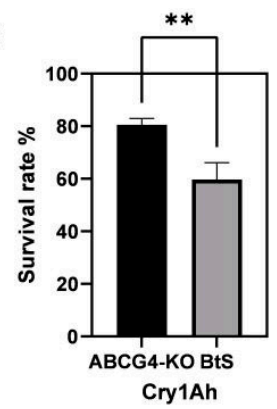

$\mathrm{F}$

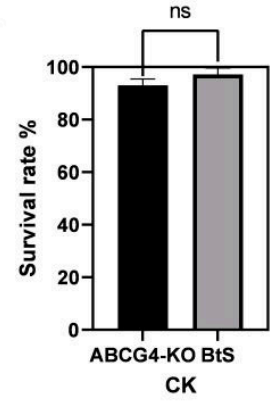

Figure 2. The survival rate of ABCG4-KO and ACB-BtS strains on five Cry1 proteins under $\mathrm{LC}_{50}$ and normal artificial diet. Survival rate of ABCG4-KO and ACB-BtS strains reared on Cry1Ab, Cry1Ac, Cry1Ah, Cry1F, and Cry1Ie protein separately (A-E). Survival rates of ABCG4-KO and ACB-BtS strains reared on normal artificial diet $(\mathbf{F}) .{ }^{* *}$ indicates extremely significant difference between ABCG4-KO and ACB-BtS strains ( $p$-value $<0.01$ ).

Table 1. The development time of ABCG4-KO and ACB-BtS strains in larvae, pupa, and adult stages.

\begin{tabular}{ccccc}
\hline \multirow{2}{*}{ Different Stages } & \multicolumn{3}{c}{ ACB-BtS } & \multicolumn{1}{c}{ ABCG4-KO } \\
\cline { 2 - 5 } & $\boldsymbol{n}$ & Development Times (d) & $\boldsymbol{n}$ & Development Times (d) \\
\hline 1st instar & 140 & $2.19 \pm 0.03 \mathrm{a}$ & 131 & $2.67 \pm 0.05 \mathrm{~b}$ \\
2nd instar & 139 & $2.81 \pm 0.03 \mathrm{a}$ & 130 & $2.34 \pm 0.04 \mathrm{~b}$ \\
3rd instar & 138 & $1.10 \pm 0.03 \mathrm{a}$ & 129 & $1.17 \pm 0.04 \mathrm{a}$ \\
4th instar & 137 & $2.00 \pm 0.03 \mathrm{a}$ & 128 & $2.03 \pm 0.04 \mathrm{a}$ \\
5th instar & 134 & $4.41 \pm 0.07 \mathrm{a}$ & 121 & $5.35 \pm 0.12 \mathrm{a}$ \\
Pupa stage & 130 & $6.71 \pm 0.05 \mathrm{a}$ & 118 & $6.76 \pm 0.08 \mathrm{a}$ \\
Adult & 111 & $6.67 \pm 0.23 \mathrm{a}$ & 102 & $7.62 \pm 0.27 \mathrm{a}$
\end{tabular}

Different letters in each row indicate significant difference between the two strains (analysis with $t$-test, $p$-value $<0.05)$.

Table 2. Pupation rates, emergency rates, and oviposition numbers per females of ABCG4-KO and ACB-BtS strains.

\begin{tabular}{cccc}
\hline Colony & $\begin{array}{c}\text { Pupation Rates } \\
\mathbf{( \% )}\end{array}$ & $\begin{array}{c}\text { Emergency Rates } \\
\mathbf{( \% )}\end{array}$ & $\begin{array}{c}\text { Oviposition Numbers } \\
\text { per Female }\end{array}$ \\
\hline ACB-BtS & $90.28 \pm 1.11 \mathrm{a}$ & $85.38 \pm 2.74 \mathrm{a}$ & $478.98 \pm 38.99 \mathrm{a}$ \\
ABCG4-KO & $81.94 \pm 2.68 \mathrm{~b}$ & $86.44 \pm 2.98 \mathrm{a}$ & $406.00 \pm 65.04 \mathrm{a}$ \\
\hline
\end{tabular}

Different letters in each column indicate significant difference between the two strains (analysis with $t$-test $p$-value $<0.05)$.

\subsection{Population Parameters of ABCG4-KO and ACB-BtS Strains}

In total, 144 individuals of the susceptible strain ACB-BtS and knockout strain ABCG4$\mathrm{KO}$ were tested separately. The intrinsic growth rate, net reproductive rate, and finite increase rate were significantly decreased in the ABCG4-KO strain. However, the mean generation time was longer in the ABCG4-KO strain than in ACB-BtS (Table 3). 
Table 3. Population parameters of ABCG4-KO and ACB-BtS strains.

\begin{tabular}{ccccc}
\hline Colony & $\begin{array}{c}\text { Mean Generation } \\
\text { Times }\end{array}$ & $\begin{array}{c}\text { Net Reproductive } \\
\text { Rates } \\
\boldsymbol{T} \text { (d) }\end{array}$ & $\begin{array}{c}\text { Intrinsic } \\
\text { Growth Rates }\end{array}$ & $\begin{array}{c}\text { Finite Increase } \\
\text { Rates } \\
\boldsymbol{r}\end{array}$ \\
\hline ACB-BtS & $26.14 \pm 0.16 \mathrm{a}$ & $161.60 \pm 24.06 \mathrm{a}$ & $0.19 \pm 0.06 \mathrm{a}$ & $1.21 \pm 0.01 \mathrm{a}$ \\
$\mathrm{ABCG} 4-\mathrm{KO}$ & $28.70 \pm 0.34 \mathrm{~b}$ & $56.53 \pm 15.56 \mathrm{~b}$ & $0.14 \pm 0.01 \mathrm{~b}$ & $1.15 \pm 0.01 \mathrm{~b}$ \\
\hline
\end{tabular}

Different letters in each column indicate significant difference between the two strains (analysis with TWOSEXMSChart, $p$-value $<0.05$ ).

\section{Discussion}

The results showed that CRISPR/Cas9 editing of the ABCG4 gene in the susceptible ACB-BtS strain significantly increased the resistance to Cry1 toxins. This information increases our understanding about the mechanism of resistance to Cry1 proteins in O. furnacalis. Nowadays, Bt-transgenic crops are used worldwide, and the biggest threat to Bt use is the target pests develop resistance [27]. Studying insect resistance mechanism will be helpful for improving Bt technology. Early studies showed that Alkaline phosphatase (ALP) [28], Aminopeptidase N (APN) [29], Cadherin (CAD) [30], and some other proteins are the receptors of $\mathrm{Bt}$ toxins [31].

Recent studies have shown that $\mathrm{ABC}$ transporters are one of the most important families related to Bt resistance. In Heliothis virescens, the mutations of the $\mathrm{ABC}$ transporter gene were found in resistant populations, and this mutation affects the binding of the Cry $1 \mathrm{~A}$ toxin to the brush-like membrane vesicles. This research suggests that the $\mathrm{ABC}$ transporter is a novel Cry1A toxin receptor that may be involved in the later stages of oligomeric membrane insertion [32]. Many $\mathrm{ABC}$ transporters associated with $\mathrm{Bt}$ resistance have been verified. The $A B C A 2$ gene was shown to confer resistance to $\mathrm{Bt}$ toxin Cry2Ab [33,34]. Zhou et al. [35] indicated that $A B C B 1$ is linked to resistance to Cry1Ac toxin in P. xylostella, and Jin et al. [36] indicated that $A B C B 6$ increases gossypol susceptibility in $H$. armigera. Zhang et al. [37] indicated that cadherin and $A B C C 2$ had synergistic resistance to Bt toxins in $H$. armigera. In addition, Guo et al. [38] showed that $A B C H 1$ was independent of Cry1Ac resistance, but the knock down of this gene could result in P. xylostella larval and pupal lethal phenotypes. Moreover, Shan et al. [39] showed that ABCG was related to chlorantraniliprole resistance in P. xylostella. Nrgri et al. [40] showed that silencing the $A B C G 4$ gene resulted in an increased pyrethroid efficacy. However, little research has been reported on how $A B C G$ is related to $B t$ resistance. Our previous study showed that the $A B C G 4$ gene was significantly down-regulated in the Cry1Ac resistant strain, indicating that the $A B C G 4$ gene was probably related to Bt resistance [25]. In the current study, we successfully knocked out the ABCG4 gene and constructed the ABCG4-KO strain. The survival rates of the ABCG4-KO strain after feeding on Cry1Ab, Cry1Ac, Cry1Ah, Cry1F, or Cry1le toxin diets were raised, and showing resistance to Cry1 proteins. This result provides evidence that the $A B C G 4$ gene is related to Cry1 protein resistance. The combined analysis of the down-regulated expression of the $A B C G 4$ gene in the resistant strain shows that $A B C G 4$ is probably a receptor of Cry1 proteins.

In transcriptome studies, hundreds of genes were found to be either up-regulated or down-regulated after pesticide treatment. The $\mathrm{ABC}$ transporter expression level changed after sublethal concentration insecticide treatments, and $80 \%$ of the significantly up-regulated $\mathrm{ABC}$ transporters were ABCGs [41], and in T. castaneum, the expression of TcABC-C9A was down-regulated after being treated with diflubenzuron [42]. In P. xylostella, the expression of four $\mathrm{ABC}$ transporter genes were up-regulated after treated with organophosphorus pesticide [43]. ABC transporters may be related to the transportation of xenobiotics/plant allelochemicals and insecticide resistance. Transcriptome analysis of the Cry1Ac resistant stain of $O$. furnacalis showed that $A B C G 1 u$ gene expression was up-regulated and $A B C G 4$ gene expression was down-regulated [25], indicating that ABCG family genes may be related to Bt resistance. 
The CRISPR/Cas9 system has been successfully used to manipulate other genes in P. xylostella and $H$. armigera to validate gene function. We used two sgRNA to knock out the ABCG4 gene in O. furnacalis, and the deletion was easily detected by PCR. In $H$. axyridis, after the $A B C G-4 C$ gene was knocked down by RNAi, most larvae died at the pupation stage with body shrinkage [24]. Furthermore, the knocked down of $A B C G-4 C$ by RNA interference was fatal in T. castaneum at the pupation stage with body shrinkage. In addition, TcABCG-4C dsRNA-injected females laid fewer eggs and failed to hatch. The lipids were depleted in larval fat body and epicuticle after RNAi. Based on these findings, Gunnar et al. [21] suggested that TCABCG-4C is involved in transporting lipids to the cuticle and is essential for the formation of a waterproof barrier in the epicuticle. Moreover, Shang et al. [44] found that ABCG4 participates in the miR-9b-ABCG4-insulin signaling pathway in aphids. Reduced $A B C G 4$ gene expression results in the incomplete development of aphid wings. In this study, as the O. furnacalis ABCG4-KO strain was still alive as the control and had no fatal effect, this indicated that $A B C G 4$ is not a lethal gene. However, the development times of young larvae (1st and 2nd instar) were significantly longer than the susceptible strain, and pupation rate was significantly lower than the susceptible strain. The $A B C G 4$ gene may be responsible for the transport of cuticle lipids, ecdysides, and other substances in the O. furnacalis. The result showed that the ABCG4 gene in O. furnacalis may have some function in the development of young larvae. In addition, the intrinsic growth rate, net reproductive rate, and finite increase rate of the average generation time was prolonged and showed obvious resistance fitness cost. O. furnacalis can decrease some gene expression to obtain Bt resistance but also needs to pay the cost, for example with prolonged development or lower pupation rate. In comparing the development time in the Cry1Ac resistant strain with the susceptible stain, the resistant strain also showed a longer development time in younger larvae (data not shown). More evidence should be provided to prove whether the shortened development time is related with Bt resistance.

O. furnacalis is harmful to corn production and is effectively controlled by transgenic maize expression Cry1A, Cry2Ab, or Cry1F, which can effectively protect against lepidopteran pests [45]. When the use of Bt crops has increased sharply, this has been shown to be an effective way to control this pest. Our work lays the foundation for understanding that the $\mathrm{ABC}$ transporter $A B C G 4$ gene plays an important role in Cry1 toxins action mode and is a receptor gene of Cry1 toxins in O. furnacalis. Furthermore, ABC transporters may also be involved in insecticide susceptibility, which can be exploited for the control of O. furnacalis. An appropriate receptor can be used as a target gene by gene edition technology in transgene corn, which can over or suppress the target gene expression, thereby decreasing its resistance to Bt proteins and prolonging the use of Bt corn.

\section{Materials and Methods}

\subsection{Insect Strains}

O. furnacalis Bt toxin susceptible strain (ACB-BtS) used in the current study was fed on artificial diet for 66 generations in the laboratory of Institute of Plant Protection, Chinese Academy of Agricultural Science (CAAS). Here, we established one knockout strain (ABCG4-KO) using the CRISPR/Cas9 genome editing tool, and both strains were reared on artificial diet with a photoperiod of $\mathrm{L} / \mathrm{D}=16: 8 \mathrm{~h}$, temperature at $27 \pm 1{ }^{\circ} \mathrm{C}$, and relative humidity at 70 80\%. For adults, 10\% sugar solution was supplied to supplement nutrition.

\subsection{Design and Preparation of Single Guide RNA ( $g g R N A$ )}

The sgRNAs used in this study were designed following the principle of N18NGG or N20NGG protospacer adjacent motif (PAM). Two sgRNAs were used to knock out the target gene $A B C G 4$; sgRNA1 and sgRNA2 were targeted at exon 5 and 6, respectively. The off target was predicted based on the similarity of genome sequences. The primers used for sgRNA synthesis are shown in Table S1. The target gene primers were mixed with DNA polymerase mix in a tube for PCR fusion. After checking the target size by $1 \%$ agarose gel electrophoresis, the PCR production was purified by DNA Purification Kit 
(Tianmo Biotech, Beijing, China). The purified DNA was used to synthesis the sgRNA by GeneArt ${ }^{\mathrm{TM}}$ Precision gRNA Synthesis Kit (Thermo Fisher Scientific, Waltham, MA, USA) following the manufacture's protocol. The concentration of purified sgRNA was measured by NanoDrop 2000 spectrophotometer (Thermo Fisher Scientific, Waltham, MA, USA) and stored at $-80{ }^{\circ} \mathrm{C}$ until use.

\subsection{Microinjection of Cas9 Protein and $s g R N A$ into Embryos}

Fresh egg masses (in $2 \mathrm{~h}$ after oviposition) were pasted on a glass slide with doublesided adhesive tape. Cas9 protein (Thermo Fisher Scientific, Waltham, MA, USA) and two sgRNA (target 1 and target 2) were mixed using the RNase-free water. Finally, the final concentration of sgRNA $(200 \mathrm{ng} / \mu \mathrm{L})$ was adjusted with Cas9 protein $(100 \mathrm{ng} / \mu \mathrm{L})$. Each embryo was injected with approximately $1 \mathrm{~nL}$ of the mix solution. After injection, the egg masses were incubated under $27 \pm 1{ }^{\circ} \mathrm{C}$ with relative humidity at $70 \sim 80 \%$ for hatching.

\subsection{Identification of ABCG4 Mutations Induced by CRISPR/Cas9}

The microinjected eggs were placed in the incubator for hatching, the neonates were maintained in the artificial diet until pupation. After emergence, one hind leg was removed to extract DNA. Meanwhile, the adult was numbered and separately fed in a plastic box, provided with 10\% honey water. Genomic DNA was extracted by M5 HiPer Mix Kit (Mei5 Biotechnology, Beijing, China) following the manufacturer's instruction. According to the sgRNA site, primers were designed flanking the CRISPR target sites to check the deletion of $A B C G 4$ gene (Table S1, Supplementary Materials). The PCR reaction system (in a total volume of $20 \mu \mathrm{L}$ ) contained $10 \mu \mathrm{L}$ of LanGene $2 \times$ Taq PCR MasterMix, $1 \mu \mathrm{L}$ of ABCG4-F, $1 \mu \mathrm{L}$ of ABCG4-R, $1 \mu \mathrm{L}$ of gDNA template, and $7 \mu \mathrm{L}$ of $\mathrm{ddH}_{2} \mathrm{O}$. The PCR program was designed as follows: $94{ }^{\circ} \mathrm{C}$ for $5 \mathrm{~min}$, followed by 36 cycles of $\left(94{ }^{\circ} \mathrm{C}\right.$ for $30 \mathrm{~s}, 56{ }^{\circ} \mathrm{C}$ for $30 \mathrm{~s}$, and $72{ }^{\circ} \mathrm{C}$ for $30 \mathrm{~s}$ ) with a final extension at $72{ }^{\circ} \mathrm{C}$ for $10 \mathrm{~min}$. All the individuals were detected by PCR separately. The single PCR production band around $359 \mathrm{bp}$ indicates a successfully knocked out homozygote, or around 676 bp indicates an unsuccessful knock out. Two bands indicated the sample are heterozygous.

\subsection{Homozygous Mutant Strain Construction}

To construct stable homozygous mutant strains ABCG4-KO, all the G0 adults were checked by PCR separately. The single band homozygote was sequenced and the corresponding adults were paired by one female and one male for reproducing to obtain G1 offspring. In total, 200 G1 adults were checked again and homozygotes were selected for hybridization to obtain more than 500 G2 progenies. The stable homozygous strain was selected from the progeny for large-scale hybridization until a stable homozygous mutant, ABCG4-KO, was established.

\subsection{Bt Toxins and Bioassays}

The Cry1Ab-, Cry1Ac-, Cry1Ah-, Cry1Ie-, and Cry1F-activated proteins used in all bioassays were provided by the Institute of Plant Protection, Chinese Academy of Agricultural Science (CAAS). Cry1 protein $\mathrm{LC}_{50}$ concentration $(0.2 \mu \mathrm{g} / \mathrm{g}, 0.2 \mu \mathrm{g} / \mathrm{g}, 0.2 \mu \mathrm{g} / \mathrm{g}$, 0.5-0.7 $\mu \mathrm{g} / \mathrm{g}$, and 3.0-5.0 $\mu \mathrm{g} / \mathrm{g}$ of Cry1Ab, Cry1Ac, Cry1Ah, Cry1F and Cry1Ie protein, respectively) was prepared with artificial diet and $\mathrm{ddH}_{2} \mathrm{O}$ [26]. The control groups were fed with normal diet without any toxins. The diet used for testing was dispensed into a 24-well plate. Three plates were set for each treatment as repetition. A single newly hatched larvae were put in each well and survival rate was recorded after 7 days. Larvae mortality on control diet did not exceed 5\%.

\subsection{Life Parameter Analysis}

The newly hatched ABCG4-KO strain and susceptible strain larvae were reared in a 24-well plate, with one larva per well and 144 individuals per strain. The 24-well plates were placed under $27 \pm 1{ }^{\circ} \mathrm{C}$, with relative humidity at 70 80\%. The growth and development 
status of the two strains were recorded every day, including larval survival rate, larva stage, pupation rate, and emergency rate. After pupation, the larvae were divided into males and females and placed in a round transparent box. The emergence adults mated in a cage $(80 \mathrm{~mm} \times 80 \mathrm{~mm} \times 100 \mathrm{~mm})$ with 1:1 ratio of male and female. Oviposition paper covered the top of the cage and a wet towel was placed on it to maintain humidity. The paper was replaced every day, and the oviposition numbers per female and adult longevity were recorded. Data analysis used TWOSEX-MSChart [46-48] and GraphPad Prism 9.0 (GraphPad, San Diego, CA, USA). The following formula was used to calculate the life table parameters

$$
\begin{gathered}
\text { Intrinsic growth rate }(r)=\left(\ln R_{0}\right) / T \\
\text { Net reproductive rate }\left(R_{0}\right)=\sum_{x=0}^{\infty} \sum_{j=l}^{m} S_{x j} f_{x j} \\
\text { Mean generation time }(T)=\left(\ln R_{0}\right) / r_{m} \\
\text { Finite increase rate }(\lambda)=e^{r m}
\end{gathered}
$$

\section{Conclusions}

This study provides a new $A B C G 4$ target gene for the sustainable utilization of transgenic plants. The $A B C G 4$ gene of the ACB was knocked out using the CRISPR/Cas9 technique, and the ACB showed higher resistance to five Cry1 proteins compared with a susceptible strain. The ABCG4 gene can influence the development of younger larvae and population parameters. Our results provide a good target gene for delaying the resistance of ACB to transgenic crops, and provide a theoretical basis for the sustainable utilization of transgenic crops.

Supplementary Materials: The following supporting information can be downloaded at: https: / / www.mdpi.com/article/10.3390/toxins14010052/s1, Table S1: Primers for sgRNA synthesis and detection of $A B C G 4$ gene deletion.

Author Contributions: Data curation, Q.G., K.H. and T.Z.; formal analysis, Z.W. and T.Z.; investigation, Q.G. and T.Z.; methodology, D.J. and T.Z.; project administration, T.Z.; resources, Q.G., Y.L. and S.B.; software, Q.G.; supervision, X.W. and Z.W.; writing-review and editing, K.H., Y.Z. and T.Z. All authors have read and agreed to the published version of the manuscript.

Funding: This research was funded by the China Agriculture Research System (CARS-02).

Institutional Review Board Statement: Not applicable.

Informed Consent Statement: Not applicable.

Data Availability Statement: All data are provided in the article and the supplementary data.

Acknowledgments: The authors are grateful to Kaiqiang Liu and Xiaohua Hu for guiding the fitness cost.

Conflicts of Interest: The authors declare that they have no conflict of interest.

\section{References}

1. Nafus, D.M.; Schreiner, I.H. Review of the biology and control of the Asian corn borer, Ostrinia furnacalis (Lep: Pyralidae). Trop. Pest Manag. 1991, 37, 41-56. [CrossRef]

2. Li, J.; Coates, B.S.; Kim, K.S.; Bourguet, D.; Ponsard, S.; He, K.; Wang, Z. The genetic structure of Asian corn borer, Ostrinia furnacalis, populations in China: Haplotype variance in Northern populations and potential impact on management of resistance to transgenic maize. J. Hered. 2014, 105, 642-655. [CrossRef] [PubMed]

3. Gregor, J.D.; Michael, J.F. Insecticide use: Contexts and ecological consequences. Agric. Hum. Values 2007, 24, 281-306.

4. Schnepf, E.; Crickmore, N.; Van Rie, J.; Lereclus, D.; Baum, J.; Feitelson, J.; Zeigler, D.R.; Dean, D.H. Bacillus thuringiensis and its pesticidal crystal proteins. Microbiol. Mol. Biol. Rev. 1998, 62, 775-806. [CrossRef] [PubMed]

5. James, C. A global overview of biotech (GM) crops: Adoption, impact and future prospects. GM Crop. 2010, 1, 8-12. [CrossRef]

6. Hofmann, C.; Lüthy, P.; Hütter, R.; Pliska, V. Binding of the delta endotoxin from Bacillus thuringiensis to brush-border membrane vesicles of the cabbage butterfly (Pieris brassicae). Eur. J. Biochem. 1988, 173, 85-91. [CrossRef] [PubMed] 
7. Mark, E.W.; Byron, A.W. Bt: Mode of action and use. Arch. Insect Biochem. Physiol. 2003, 54, $200-211$.

8. Tabashnik, B.E.; Cushing, N.L.; Finson, N.N.; Johnson, M.W. Field development of resistance to Bacillus thuringiensis in diamondback moth (Lepidoptera: Plutellidae). J. Econ. Èntomol. 1990, 83, 1671-1676. [CrossRef]

9. Janmaat, A.F.; Myers, J. Rapid evolution and the cost of resistance to Bacillus thuringiensis in greenhouse populations of cabbage loopers, Trichoplusia ni. Proc. R. Soc. Lond. Ser. B 2003, 270, 2263-2270. [CrossRef] [PubMed]

10. Tabashnik, B.E.; Carrière, Y. Surge in insect resistance to transgenic crops and prospects for sustainability. Nat. Biotechnol. 2017, 35, 926-935. [CrossRef] [PubMed]

11. Tabashnik, B.E.; Carrière, Y. Global patterns of resistance to Bt crops highlighting pink bollworm in the United States, China, and India. J. Econ. Ėntomol. 2019, 112, 2513-2523. [CrossRef] [PubMed]

12. Calles-Torrez, V.; Knodel, J.J.; Boetel, M.A.; French, B.W.; Fuller, B.W.; Ransom, J.K. Field-evolved resistance of northern and western corn rootworm (Coleoptera: Chrysomelidae) populations to corn hybrids expressing single and pyramided Cry3Bb1 and Cry34/35Ab1 Bt proteins in North Dakota. J. Econ. Entomol. 2019, 112, 1875-1886. [CrossRef] [PubMed]

13. Tabashnik, B.E.; Brévault, T.; Carrière, Y. Insect resistance to Bt crops: Lessons from the first billion acres. Nat. Biotechnol. 2013, 31, 510-521. [CrossRef] [PubMed]

14. Gholamreza, S.J.; Elena, V.; Reza, S. Bacillus thuringiensis: A successful insecticide with new environmental features and tidings Appl. Microbiol. Biotechnol. 2017, 101, 2691-2711.

15. Labbe, R.; Caveney, S.; Donly, C. Genetic analysis of the xenobiotic resistance associated ABC gene subfamilies of the Lepidoptera. Insect Mol. Biol. 2010, 20, 243-256. [CrossRef] [PubMed]

16. Sun, H.; Pu, J.; Chen, F.; Wang, J.; Han, Z. Multiple ATP-binding cassette transporters are involved in insecticide resistance in the small brown planthopper, Laodelphax striatellus. Insect Mol. Biol. 2017, 26, 343-355. [CrossRef] [PubMed]

17. Zhu, F.; Gujar, H.; Gordon, J.R.; Haynes, K.F.; Potter, M.F.; Palli, S.R. Bed bugs evolved unique adaptive strategy to resist pyrethroid insecticides. Sci. Rep. 2013, 14, 1456. [CrossRef]

18. Guo, Z.J.; Sun, D.; Kang, S.; Zhou, J.L.; Gong, L.J.; Qin, J.Y.; Guo, L.; Zhu, L.H.; Bai, Y.; Luo, L.; et al. CRISPR/Cas9 mediated knockout of both the PxABCC2 and PxABCC3 genes confers high-level resistance to Bacillus thuringiensis Cry1Ac toxin in the diamondback moth, Plutella xylostella (L.). Insect Biochem. Mol. Biol. 2019, 107, 31-38. [CrossRef]

19. Jin, M.; Yang, Y.; Shan, Y.; Chakrabarty, S.; Cheng, Y.; Soberón, M.; Bravo, A.; Liu, K.; Wu, K.; Xiao, Y. Two ABC transporters are differentially involved in the toxicity of two Bacillus thuringiensis Cry1 toxins to the invasive crop-pest Spodoptera frugiperda (J. E Smith). Pest Manag. Sci. 2020, 77, 1492-1501. [CrossRef]

20. Wang, J.; Ma, H.; Zhao, S.; Huang, J.; Yang, Y.; Tabashnik, B.E.; Wu, Y. Functional redundancy of two ABC transporter proteins in mediating toxicity of Bacillus thuringiensis to cotton bollworm. PLoS Pathog. 2020, 16, e1008427. [CrossRef]

21. Gunnar, B.; Tobias, K.; Marcé, L.; Hans, M. Function analysis of the ATP-binding cassette (ABC) transporter gene family of Tribolium castaneum. BMC Genomics 2013, 14, 1471-2164.

22. Mummery-Widmer, J.L.; Yamazaki, M.; Stoeger, T.; Novatchkova, M.; Bhalerao, S.; Chen, D.; Dietzl, G.; Dickson, B.J.; Knoblich, J.A. Genome-wide analysis of Notch signalling in Drosophila by transgenic RNAi. Nature 2009, 458, 987-992. [CrossRef] [PubMed]

23. Ewart, G.D.; Howells, A.J. ABC transporters involved in transport of eye pigment precursors in Drosophila melanogaster. Methods Enzymol. 1998, 292, 213-224. [CrossRef]

24. Tsuji, T.; Gotoh, H.; Morita, S.; Hirata, J.; Minakuchi, Y.; Yaginuma, T.; Toyoda, A.; Niimi, T. Molecular characterization of eye pigmentation-related $\mathrm{ABC}$ transporter genes in the ladybird beetle Harmonia axyridis reveals striking gene duplication of the white gene. Zool. Sci. 2018, 35, 260-267. [CrossRef] [PubMed]

25. Zhang, T.; Coates, B.S.; Wang, Y.; Wang, Y.; Bai, S.; Wang, Z.; He, K. Down-regulation of aminopeptidase N and ABC transporter subfamily $\mathrm{G}$ transcripts in Cry1Ab and Cry1Ac resistant Asian corn borer, Ostrinia furnacalis (Lepidoptera: Crambidae). Int. J. Biol. Sci. 2017, 13, 835-851. [CrossRef]

26. Wang, Y.; Wang, Y.; Wang, Z.; Alejandra, B.; Mario, S.; He, K. Genetic basis of Cry1F-resistance in a laboratory selected Asian corn borer strain and its cross-resistance to other Bacillus thuringiensis toxins. PLoS ONE 2016, 11, e0161189. [CrossRef]

27. Jurat-Fuentes, J.L.; Heckel, D.G.; Ferré, J. Mechanisms of resistance to insecticidal proteins from Bacillus thuringiensis. Annu. Rev. Èntomol. 2021, 66, 121-140. [CrossRef]

28. Caccia, S.; Moar, W.J.; Chandrashekhar, J. Association of CrylAc toxin resistance in Helicoverpa zea (Bod die) with increased alkaline phosphatase levels in the midget lumen. Appl. Environ. Microbiol. 2012, 78, 5690-5698. [CrossRef] [PubMed]

29. Tiewsiri, K.; Wang, P. Differential alteration of two aminopeptidases $\mathrm{N}$ associated with resistance to Bacillus thuringiensis toxin CrylAc in cabbage looper. Proc. Natl. Acad. Sci. USA 2011, 108, 14037-14042. [CrossRef]

30. Jin, T.; Chang, X.; Catehouse, A.; Wang, Z.; Edwards, M.; He, K. Down regulation and mutation of a cadherin gene associated with CrylAc resistance in the Asian corn borer, Ostrinia. furnacalis (Guenée). Toxins 2014, 6, 2676-2693. [CrossRef]

31. Yannick, P.; Anne, B.; Sylvie, A.; David, G.H. A P-Glycoprotein is linked to resistance to the Bacillus thuringiensis Cry3Aa toxin in a leaf beetle. Toxins 2016, 8, 362 .

32. Gahan, L.J.; Pauchet, Y.; Vogel, H.; Heckel, D.G. An ABC transporter mutation is correlated with insect resistance to Bacillus thuringiensis Cry1Ac toxin. PLoS Genet. 2010, 6, e1001248. [CrossRef]

33. Yang, X.; Chen, W.; Song, X.; Ma, X.; Cotto-Rivera, R.O.; Kain, W.; Chu, H.; Chen, Y.-R.; Fei, Z.; Wang, P. Mutation of ABC transporter ABCA2 confers resistance to Bt toxin Cry2Ab in Trichoplusia ni. Insect Biochem. Mol. Biol. 2019, 112, 103209. [CrossRef] [PubMed] 
34. Fabrick, J.A.; LeRoy, D.M.; Mathew, L.G.; Wu, Y.; Unnithan, G.C.; Yelich, A.J.; Carrière, Y.; Li, X.; Tabashnik, B.E. CRISPR-mediated mutations in the ABC transporter gene ABCA2 confer pink bollworm resistance to Bt toxin Cry2Ab. Sci. Rep. 2021, 11, 10377. [CrossRef] [PubMed]

35. Zhou, J.; Guo, Z.; Kang, S.; Qin, J.; Gong, L.; Sun, D.; Guo, L.; Zhu, L.; Bai, Y.; Zhang, Z.; et al. Reduced expression of the P-glycoprotein gene PXABCB1 is linked to resistance to Bacillus thuringiensis Cry1Ac toxin in Plutella xylostella (L.). Pest Manag. Sci. 2019, 76, 712-720. [CrossRef]

36. Jin, M.; Cheng, Y.; Guo, X.; Li, M.; Chakrabarty, S.; Liu, K.; Wu, K.; Xiao, Y. Down-regulation of lysosomal protein ABCB6 increases gossypol susceptibility in Helicoverpa armigera. Insect Biochem. Mol. Biol. 2020, 122, 103387. [CrossRef] [PubMed]

37. Zhang, D.; Jin, M.; Yang, Y.; Zhang, J.; Yang, Y.; Liu, K.; Soberón, M.; Bravo, A.; Xiao, Y.; Wu, K. Synergistic resistance of Helicoverpa armigera to Bt toxins linked to cadherin and ABC transporters mutations. Insect Biochem. Mol. Biol. 2021, 137, 103635. [CrossRef]

38. Guo, Z.; Kang, S.; Zhu, X.; Xia, J.; Wu, Q.; Wang, S.; Xie, W.; Zhang, Y. The novel ABC transporter ABCH1 is a potential target for RNAi-based insect pest control and resistance management. Sci. Rep. 2015, 5, 13728. [CrossRef]

39. Shan, J.; Sun, X.; Li, R.; Zhu, B.; Liang, P.; Gao, X. Identification of ABCG transporter genes associated with chlorantraniliprole resistance in Plutella xylostella (L.). Pest Manag. Sci. 2021, 77, 3491-3499. [CrossRef]

40. Negri, A.; Ferrari, M.; Nodari, R.; Coppa, E.; Mastrantonio, V.; Zanzani, S.; Porretta, D.; Bandi, C.; Urbanelli, S.; Epis, S. Gene silencing through RNAi and antisense vivo-Morpholino increases the efficacy of pyrethroids on larvae of Anopheles stephensi. Malar. J. 2019, 18, 294. [CrossRef]

41. He, C.; Liang, J.; Liu, S.; Wang, S.; Wu, Q.; Xie, W.; Zhang, Y. Changes in the expression of four ABC transporter genes in response to imidacloprid in Bemisia tabaci Q (Hemiptera: Aleyrodidae). Pestic. Biochem. Physiol. 2019, 153, 136-143. [CrossRef] [PubMed]

42. Merzendorfer, H.; Kim, H.S.; Chaudhari, S. Genomic and proteomic studies on the effects of the insect growth regulator diflubenzuron in the model beetle species Tribolium castaneum. Insect Biochem. Mol. Biol. 2012, 42, 264-276. [CrossRef] [PubMed]

43. Hsu, J.C.; Lin, Y.Y.; Chang, C.C.; Hua, K.H.; Chen, M.J.M.; Huang, L.H.; Chen, C.Y. Discovery of organophosphate resistancerelated genes associated with well-known resistance mechanisms of Plutella xylostella (L.) (Lepidoptera: Plutellidae) by RNA-Seq. J. Econ. Entomol. 2016, 109, 1378-1386. [CrossRef]

44. Shang, F.; Niu, J.; Ding, B.-Y.; Zhang, W.; Wei, D.-D.; Wei, D.; Jiang, H.-B.; Wang, J.-J. The miR-9b microRNA mediates dimorphism and development of wing in aphids. Proc. Natl. Acad. Sci. USA 2020, 117, 8404-8409. [CrossRef]

45. Christou, P.; Capell, T.; Kohli, A.; Gatehouse, J.; Gatehouse, A. Recent developments and future prospects in insect pest control in transgenic crops. Trends Plant Sci. 2006, 11, 302-308. [CrossRef]

46. Chi, H.; Liu, H. Two new methods for the study of insect population ecology. Acad. Sin. 1985, 24, 225-240.

47. Chi, H. Life-Table Analysis Incorporating Both Sexes and Variable Development Rates Among Individuals. Environ. Èntomol. 1988, 17, 26-34. [CrossRef]

48. Chi, H. TWOSEX-MSChart: A Computer Program for the Age-Stage, Two-Sex Life Table Analysis; National Chung Hsing University: Taichung, Taiwan, 2020. 